\title{
Numerical investigation of the effect of constrained groove pressing process on the mechanical properties of polyamide PA66
}

\author{
Mohammed Salah Bennouna \\ University of Kasdi Merbah ouargla, Algeria \\ Bennouna_ms@yahoo.fr,bttp://orcid.org/0000-0002-3694-9993
}

Sadek Kaddour, Aour Benaoumeur

Labab Laboratory, ENPOran, Algeria

sadekkaddoun@gmail.com,ben_aoun@yaboo.fr

Damba Nadir

University of Adrar, Algeria

Boudjmaa.damba@yahoo.fr

\begin{abstract}
This research is a numerical study of the effect of the constrained groove pressing (CGP) process and its impact on a thermoplastic polymer (polyamide PA 66). A simulation is performed using a finite element tool. The effect of the process conditions and the tool geometry on the mechanical properties is noted. The results are significant, the equivalent strain and Von Mises stress have been progressed accordingly to the number of cycles and the tool geometry. Concluding remarks on the alteration of the microstructure have been proclaimed at the end of this paper.
\end{abstract}

KEYwORDS. FEA method; Polymer; Stress; Strain; CGP; SPD.

\section{OPEN ACCESS}

Citation: Bennouna, M. S., Kaddur, S., Aour, B., Damba, N.,. Numerical investigation of the effect of constrained groove pressing process on the mechanical properties of polyamide PA66, Frattura ed Integrità Strutturale, 51 (2020) 254-266.

Received: 30.08 .2019

Accepted: 26.11 .2019

Published: 01.01.2020

Copyright: (C) 2020 This is an open access article under the terms of the CC-BY 4.0, which permits unrestricted use, distribution, and reproduction in any medium, provided the original author and source are credited.

\section{INTRODUCTION}

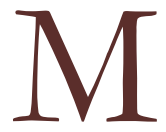
any research works have been carried out on Several Super Plastic Deformation (SPD) processes to introduce a large plastic deformation into bulk materials to give them an ultra-fine grained structure. These processes are used in the industry as metal forming processes but in this work we are using one of these processes (CGP) on polymeric materials to improved mechanical and physical properties which destine them for a wide commercial use such as biomechanical materials. 
Nowadays it is evident that the numerical approach completes the experimental one in the research activity. In this context comes the present study which completes a detailed experimental study of the effect of CGP on polymer (PA66) was carried out and published by Bennouna et al [1].

Note that the CGP process is performed with two tools, a corrugating one for applying intense plastic deformation to material and a straightening one to restore the straight shape of the sample.

This study applies the FEM (finite element method) approach which is widely applied by researchers. Among the most successful applications this method we find the modeling of the deformation of material [2-5].

Noting that deformation, rate of deformation and chemical composition are parameters which have a significant effect on the mechanical properties of the material $[6,7]$.

Many phenomenological models have been used to simulate the intense plastic deformation of polymeric materials such as those used by Bardenhagen et al [8], Frank and Brockman [9], Colak [10] and which has been by several researchers such as Aour et al. [11-13], Mitsak [14] and Draï and Aour [15] and that used by Estrin et al and improved by Mckenzie et al [16] and also by Hosseini and Kazminezhad [17].

Simulating intense deformations such as those induced by the CGP process using finite element is a very complex operation that those of small deformations because introducing simple definitions such as isotropic hardening or perfectly plastic conditions do not lead to precise results to see acceptable [18]. To describe the plastic deformation behavior of polymeric materials many constitutive models have been used by searchers to simulate semi crystalline Polymers with a finite element tool such as abaqus.

In general these models are based on the additive decomposition of the strain rate tensor $\mathrm{d}$ into an elastic part de and a viscoplastic part dvp:

$$
\mathrm{d}=\mathrm{d}^{\mathrm{e}}+\mathrm{d}^{\mathrm{vp}}
$$

Note that a single pressing of CGP process yields a shear strain of $\gamma=h / h=1$ (where $h$ is the groove wide) at deformed region. This is equivalent to an effective strain

$$
\varepsilon_{\mathrm{eff}}=\sqrt{\frac{4\left(\frac{\gamma}{2}\right)^{2}}{3}}=0.58
$$

But the present simulation was carried out by injecting into the modeling; the true parameters extracted from the experimental tests and corrected using the correction factor of the machine which leads to engineering values.

For this reason, experimental tensile tests were performed on PA66 samples to obtain the stress-strain curve shown in Fig. 1 [1].

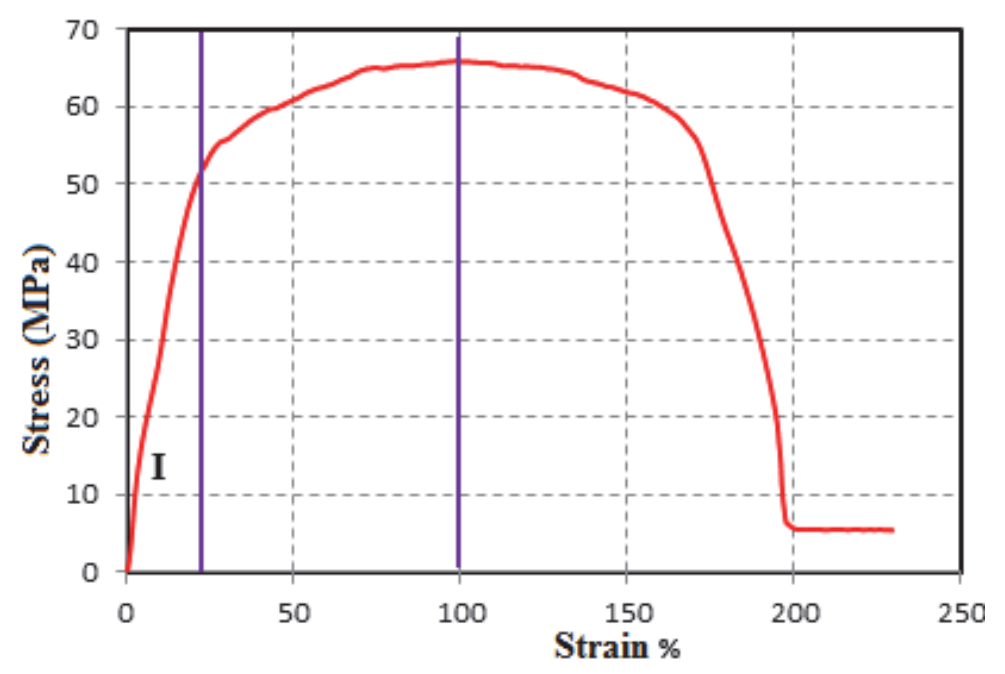

Figure 1: Stress-strain curve obtained from a tensile test on PA66 polyamide [1]. 


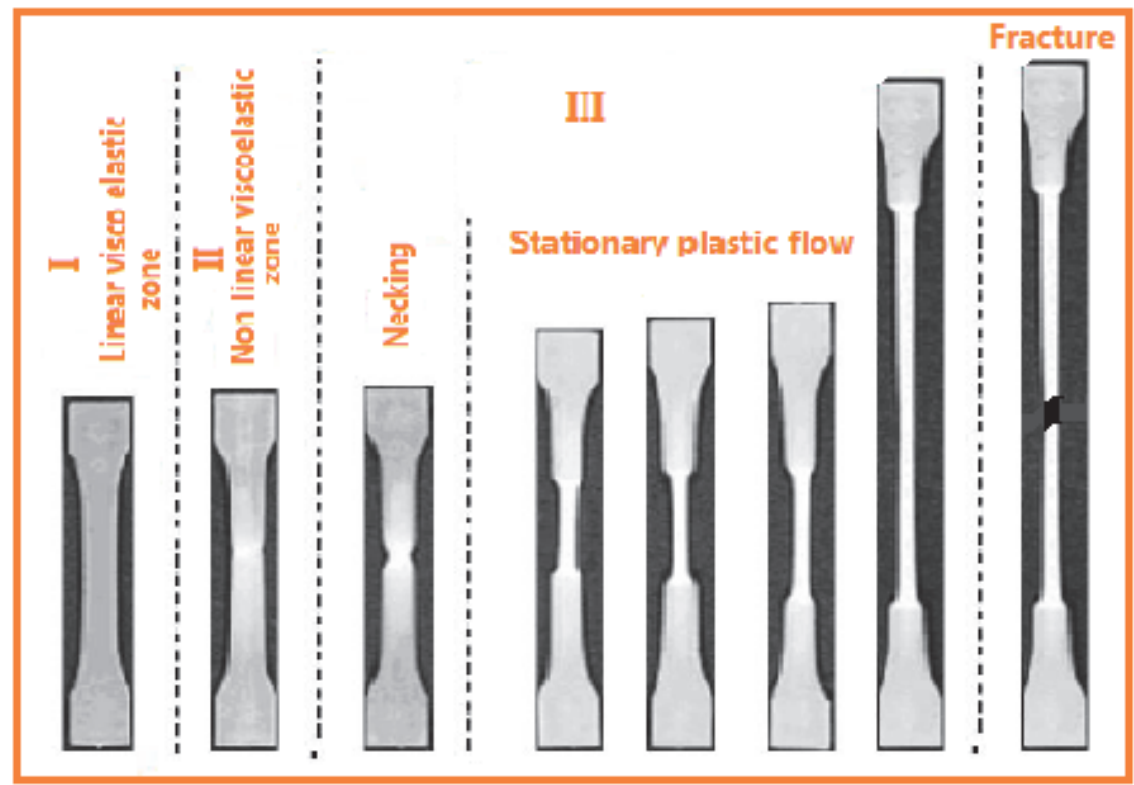

Figure 2: Different phases that the sample undergo during the tensile test.

Fig. 1and Fig.2 show that the deformation of the material passes through three different phases: the first (I) is a phase of elastic deformation, the second (II) is a phase of plastic deformation with a low strain hardening, and in the third phase (III), a softening was noted (stress drop) which results of the high ductility of this polymer, which determines a fast lowering stress, but this is due to the use of engineering strains. Data of this experimental curve are used for the numerical simulation.

\section{MATERIAL AND METHODS}

7 he simulations were run using Abaqus, an FE tool. The initial dimensions of the PA66 sample used are the same as those used in the experimental study carried out and published by Bennouna et al $(87 \times 45 \times 3 \mathrm{~mm})$, (2018) [1].

The same boundary conditions were also used with a mesh of 4935 4-node quadrilateral elements of the CPE4R type (four- node plane strain element) (Fig. 3). Note that true strains values are used for the simulation and not nominal values.

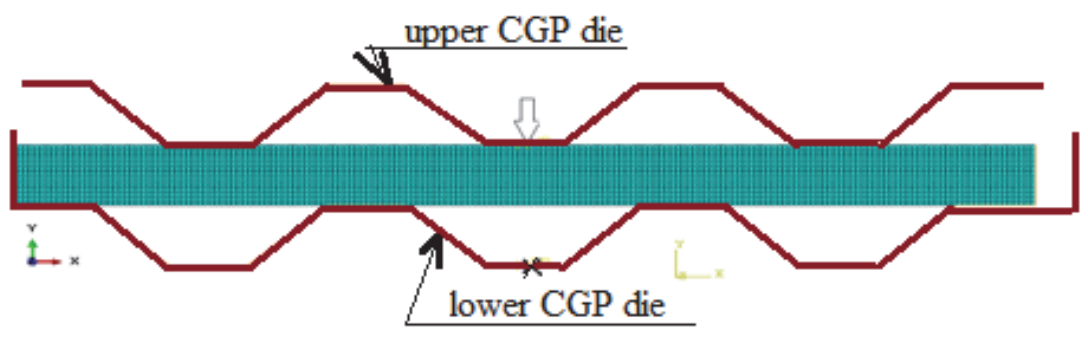

Figure 3: Finite element discretization of samples.

As shown in Fig. 4 pure shear occurs in the inclined areas of the sample but some regions remain undeformed, which means that the microstructure has certain heterogeneity (Fig 5). To overcome this disadvantage and introduce a uniform deformation in the workpiece, the sample is placed on the right side of tool during one cycle and then pushed to the left side during the next cycle. The friction metal/polymer was considered in the simulation although the surfaces of the dies and samples were polished to reduce it. 


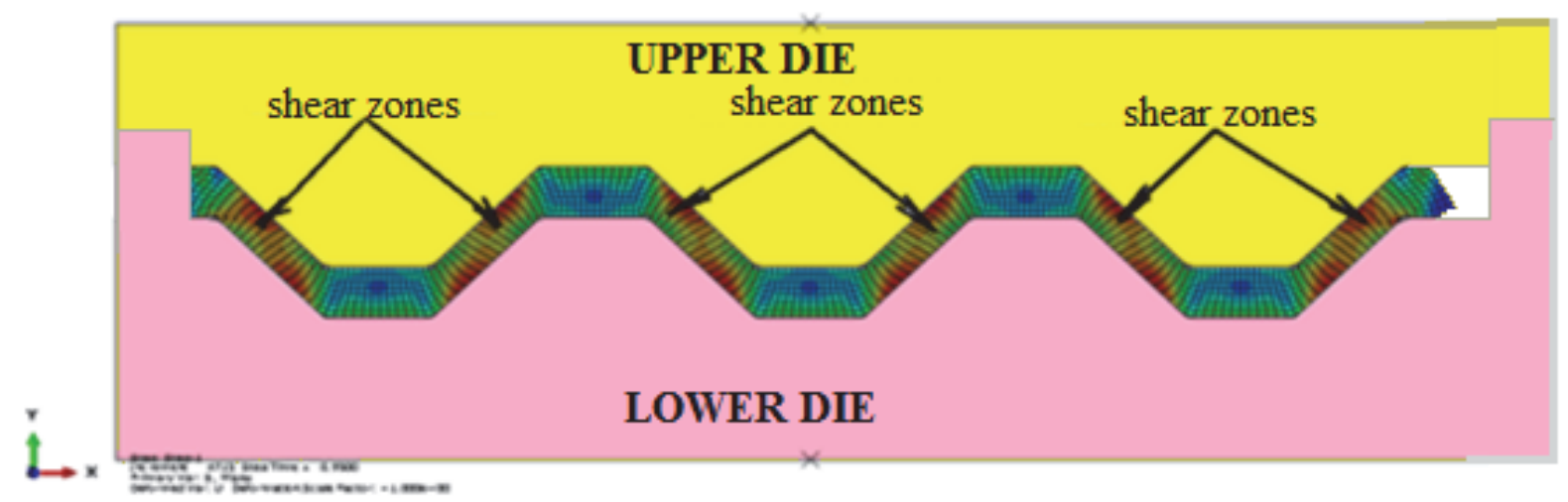

Figure 4: Illustration of the plastic deformation zones during the CGP process.

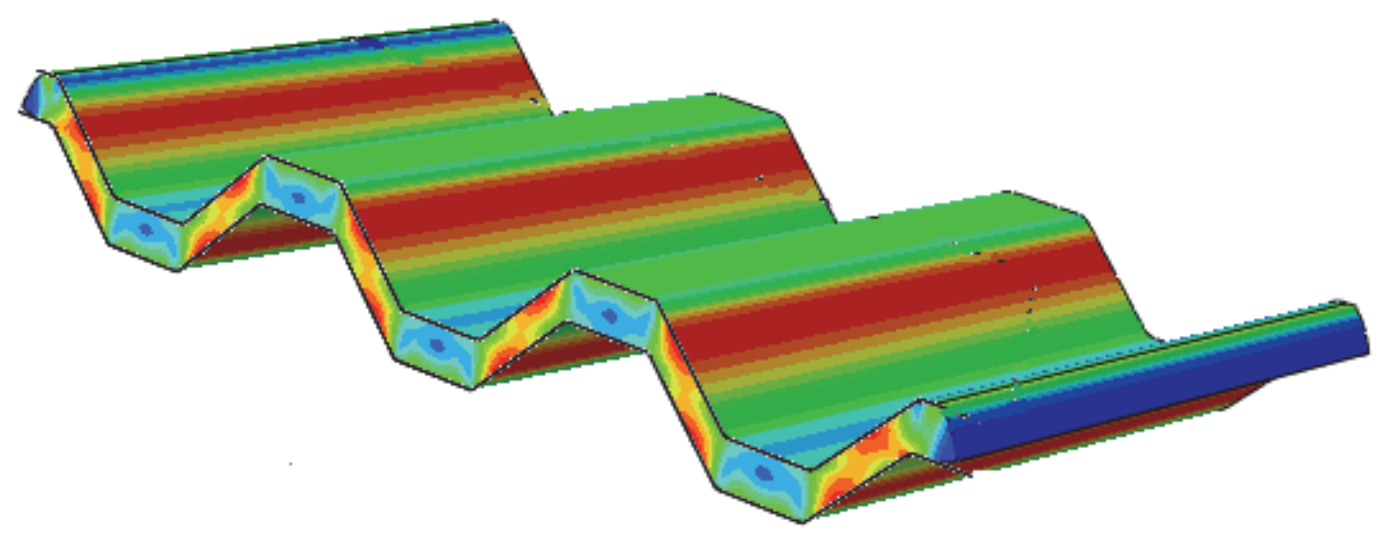

Figure 5: Sample after plastic deformation of the CGP process.

\section{RESULT AND DISCUSSION}

Influence of the number of cycles

1 o demonstrate how the number of cycles affects the equivalent strain that different surfaces of the samples undergo (Fig.6) the process was repeated three times (cycles). The results obtained for the different cycles are illustrated in Figs. 7 to 12.

Fig.7 illustrates the evolution of Voe Mises during three different cycles of CGP.

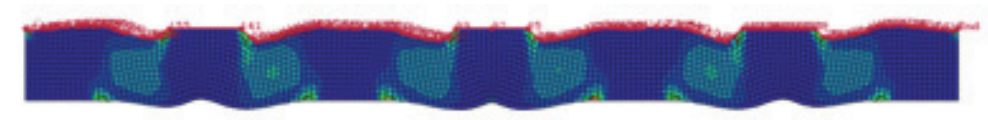

(a) Upper path

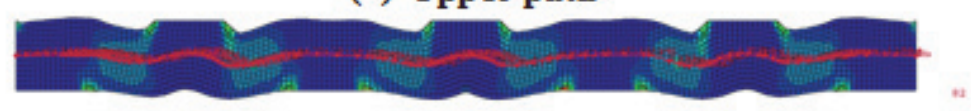

(b) Midle path

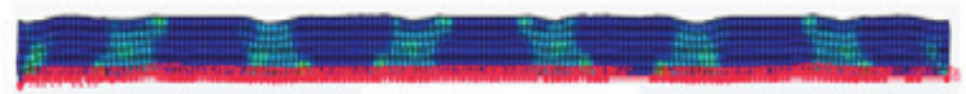

(c) Lower path

Figure 6: Different paths selected for study. 


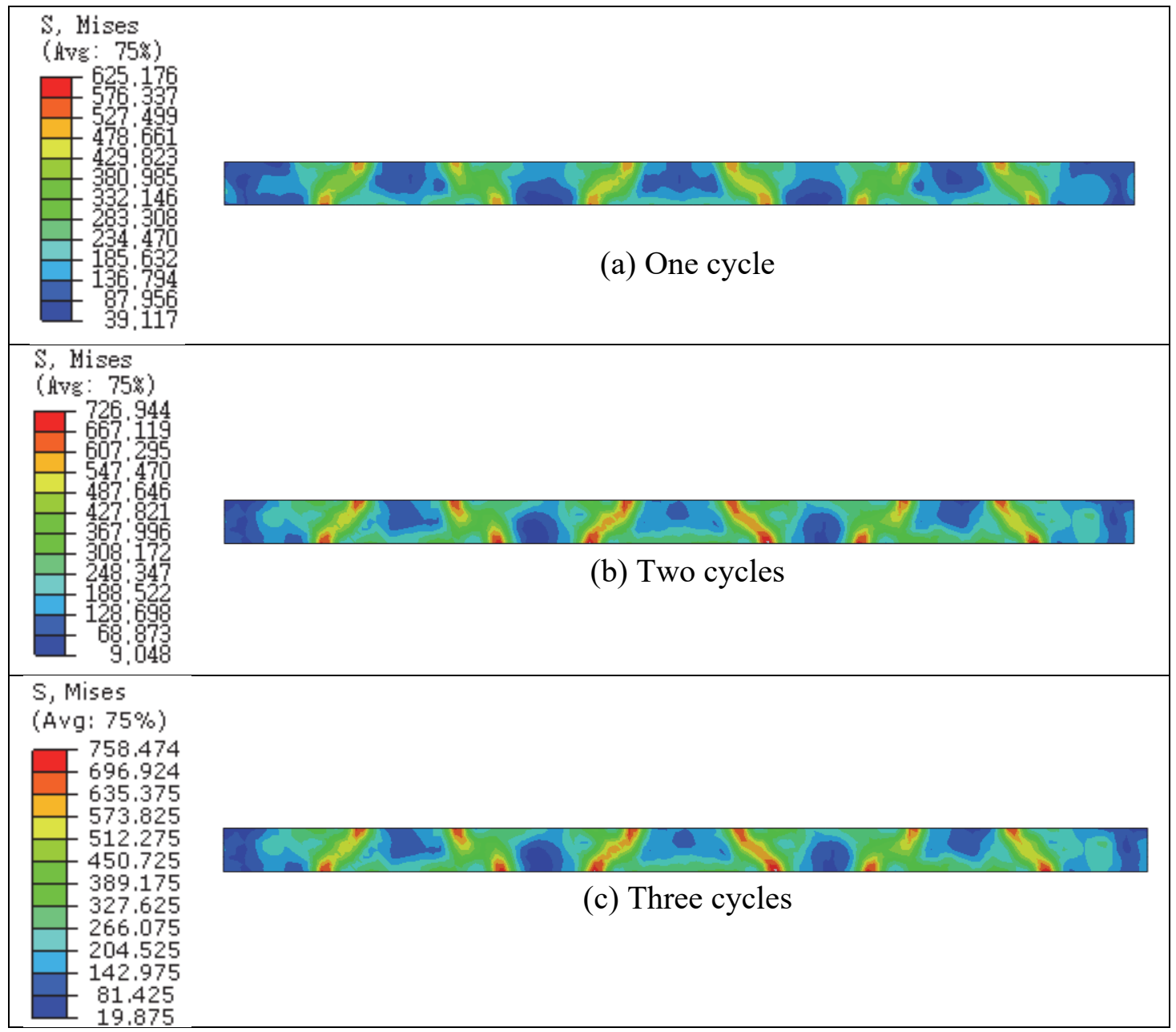

Figure 7: Distribution of Von Mises constraints for different numbers of cycles.

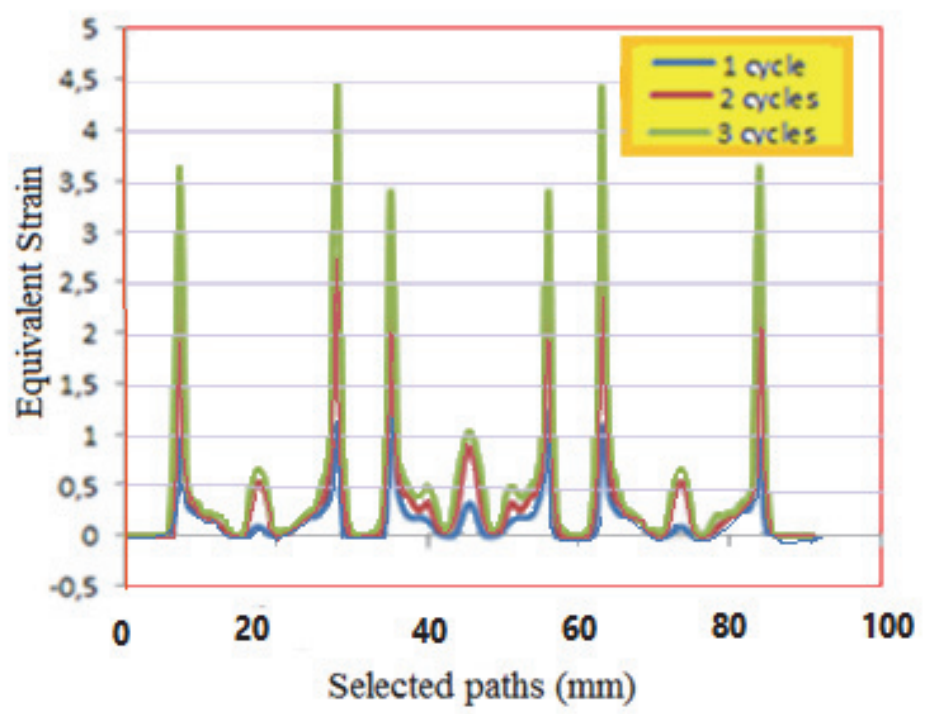

Figure 8: Influence of the number of cycles on the evolution of the plastic strain at the level of the upper surface. 
Case of a path of the upper face

The equivalent strain on the upper surface increases progressively with the number of cycles, the maximum value goes from 1.25 in the first cycle to 4.5 in the third cycle (Fig. 8).

Case of a path of the middle face

As for the upper surface, the value of the equivalent plastic strain induced by the median path increases with the number of cycles applied but with less values than those induced by the upper surface. Indeed, the maximum value of the equivalent plastic strain does not exceed 0.81 in the third cycle (Fig. 9).

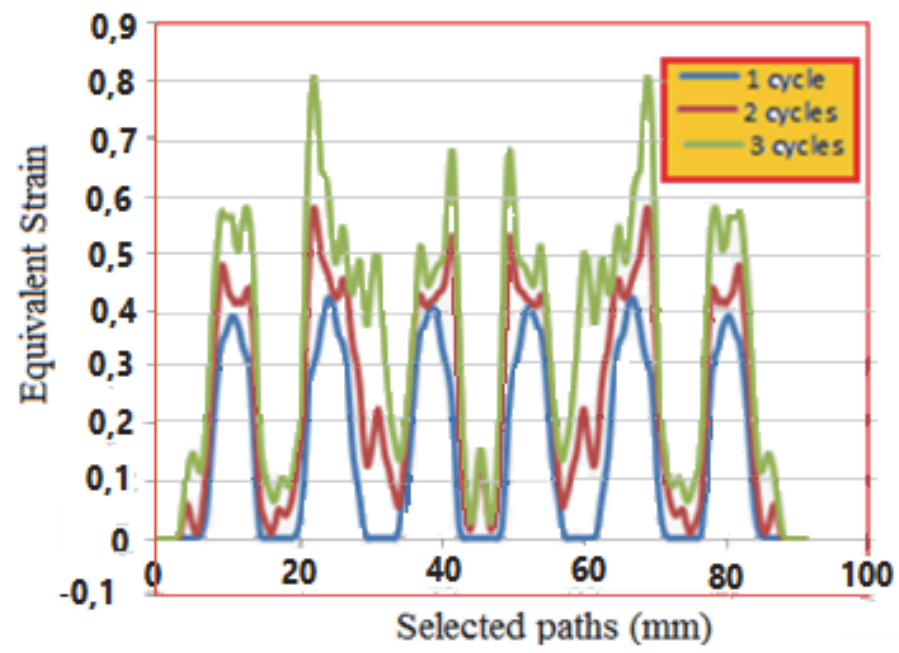

Figure 9: Influence of the number of cycles on the evolution of the plastic strain at the level of the median surface of the sample.

\section{Case of a path of the lower face}

The equivalent plastic strain at the bottom surface of the sample increases gradually with the number of cycles. Indeed, the maximum value goes from 0.9 for the first cycle to 3.45 for the third cycle (Fig. 10).

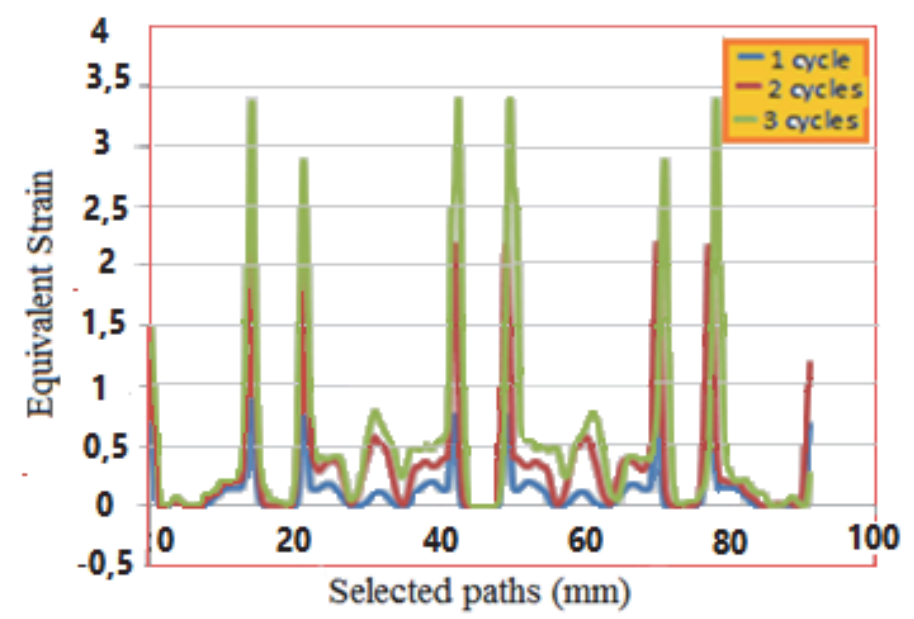

Figure 10: Influence of the number of cycles on the evolution of the plastic strain at the level of the upper surface.

Fig. 11 presents a comparison between the evolutions of the equivalent plastic strain introduced by the number of CGP cycles at the different paths selected in the sample. It is clear that the equivalent plastic strain increases progressively with the number of cycles for the three types of selected paths. We can also see that the equivalent plastic strain in the middle of the sample is very small compared to the other two surfaces for the case of the three cycles and that the lower surface keep the same value of equivalent plastic strain during the second and the third cycles. 


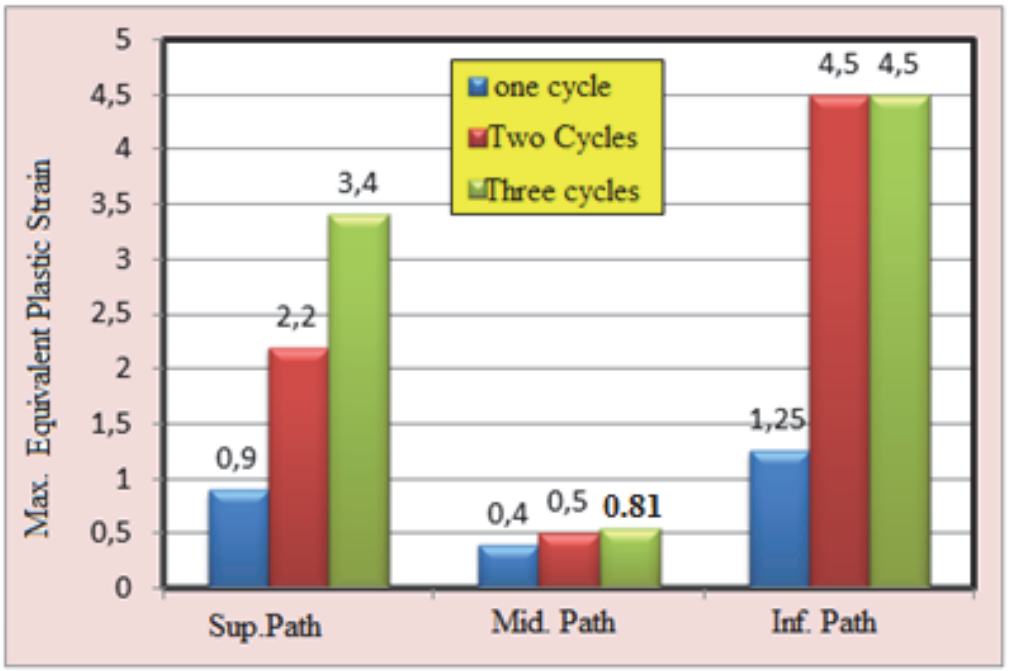

Figure 11: Evolution of maximal equivalent plastic strain along the selected paths, for different numbers of cycles.

Influence of the groove angle

In this section, we will evaluate the influence of the dimensions of the groove of the tool on the equivalent plastic strain at the level of the different paths. For this reason, we selected three different values $\left(30^{\circ}, 45^{\circ}\right.$ and $\left.60^{\circ}\right)$ for the angle $\beta$ as shown in Fig. 12.

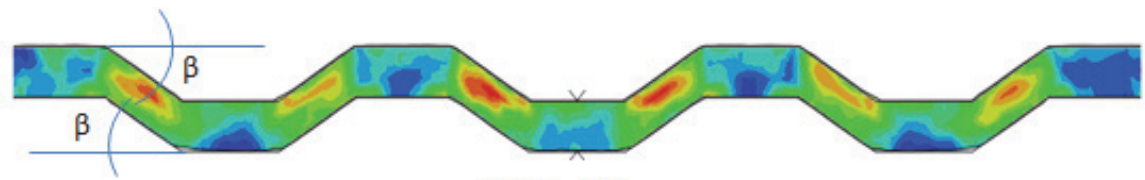

(a) $\beta=30^{\circ}$

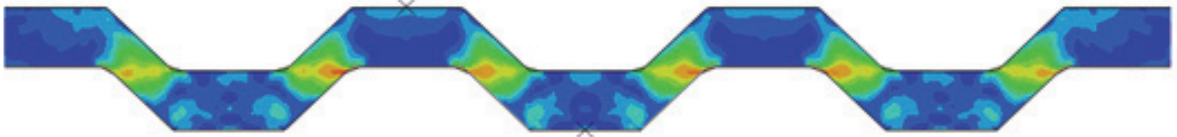

(b) $\beta=45^{\circ}$

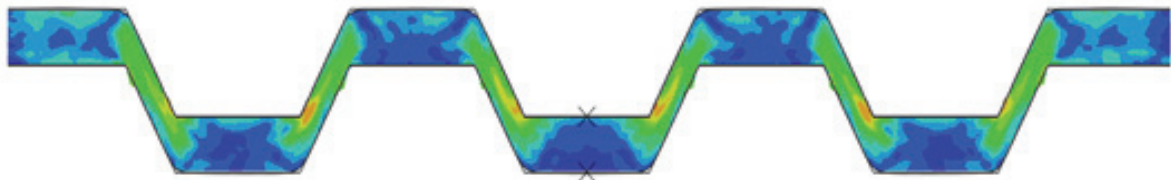

(c) $\beta=60^{\circ}$

Figure 12: Illustration of the different values of the angle $\beta$ of the tool groove.

The depth of the groove was fixed to $7 \mathrm{~mm}$. The results of the third cycle obtained for the three different selected trajectories (lower, middle and upper) are presented respectively in Figs. 13, 14 and 15.

Case of a path of the upper face

According to Fig. 13, it is the tool of $60^{\circ}$ which ensures a higher equivalent plastic strain for the upper surface with a maximum value equal to 2.4 , whereas, the weakest values are obtained at an angle of $30^{\circ}$.

Case of a path of the middle face

In this case, we note that the angle of $60^{\circ}$ is the one which ensures the maximum of equivalent plastic strain with a value of 2.4 (Fig.14), whereas, the low values are obtained with the angle $30^{\circ}$. 


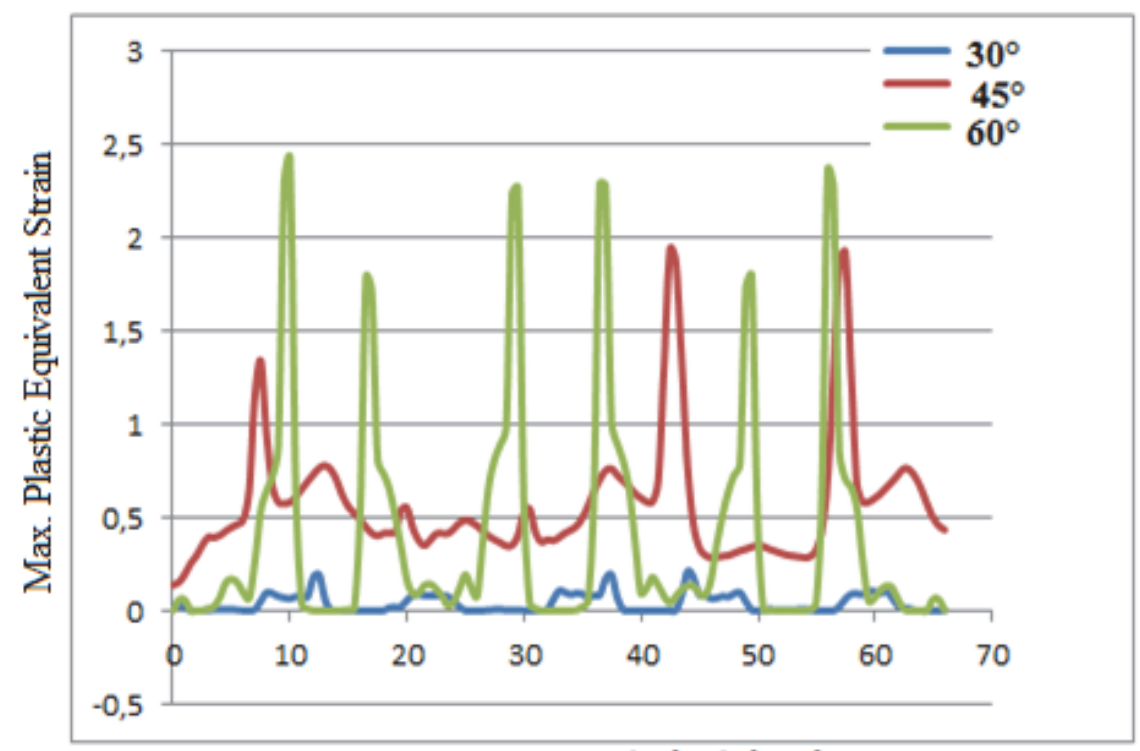

Path on the upper surface

Figure 13: Evolution of the equivalent plastic strain for a path of the upper surface using different angles of grooves.

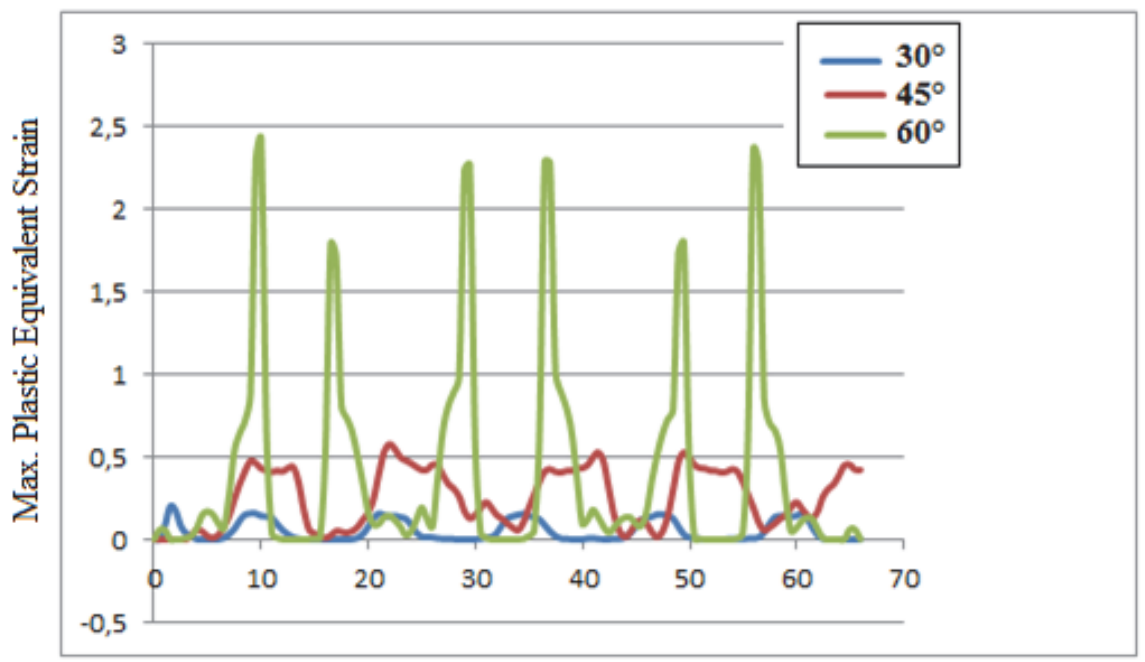

Path of the median surface

Figure 14: Evolution of the equivalent plastic strain for a trajectory in the median of the sample using different angles of grooves.

Case of a path of the lower face

Fig. 15 illustrates the evolution of the equivalent plastic strain along the lower path for different angles of the groove of the dies. It may be noted that the angle of $45^{\circ}$ is the one which ensures the maximum of plastic strain on this surface of the sample with a maximum value equal to 1.8, while the low values are obtained with the angle of $60^{\circ}$.

It is visibly clear that the angle of $60^{\circ}$ ensures higher plastic strain than the ones of $30^{\circ}$ and $45^{\circ}$ for the upper surface and the middle surface of the sample. For the lower surface, it is the angle of $45^{\circ}$ which ensures a maximum value of equivalent plastic strain. It can also be seen from Fig. 16 that the value of the deformation increases progressively with the value of the angle with the exception of the lower surface.

\section{Influence of the depth of the groove}

To evaluate the influence of the groove depth on the process results, the value of the angle $\beta$ was fixed to $45^{\circ}$ by varying the value of the depth of the groove $H$. Three different values were used $(3 \mathrm{~mm}, 5 \mathrm{~mm}$ and $8 \mathrm{~mm})$ as shown in Fig. 17 . 


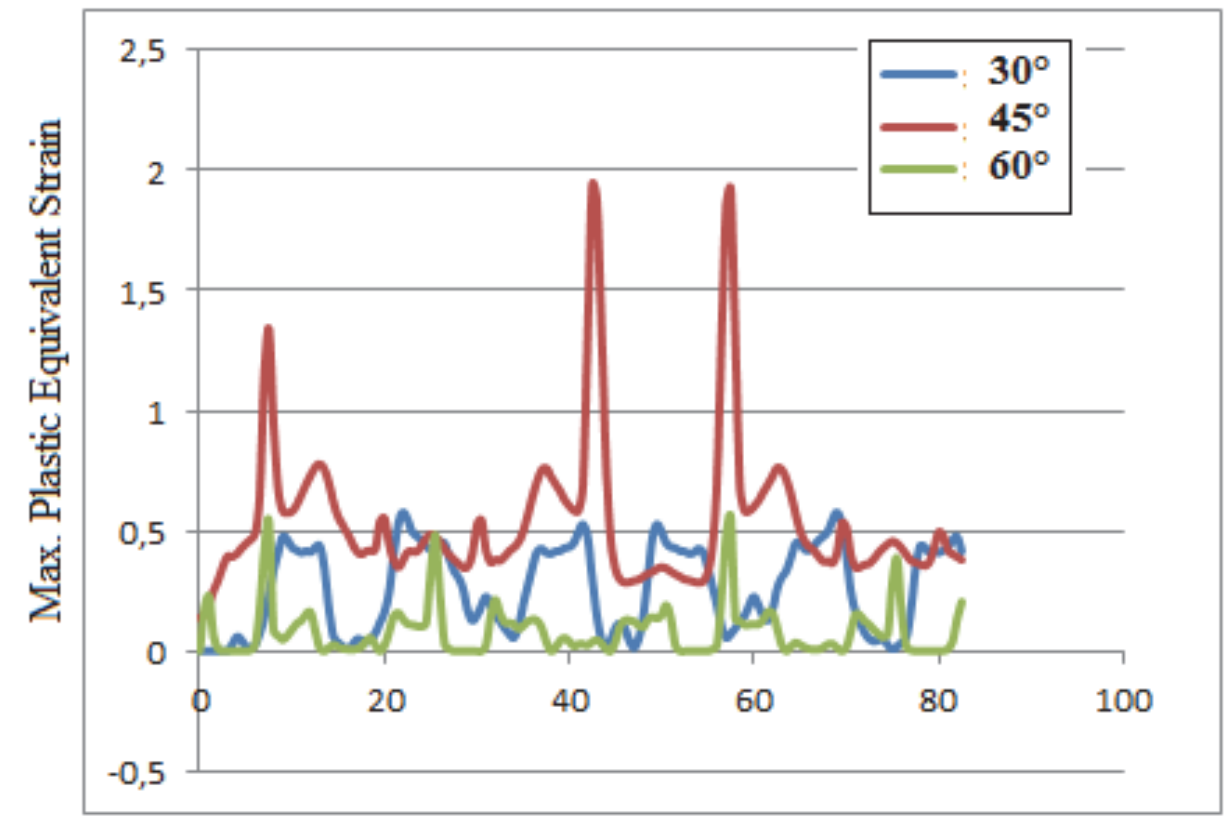

Path of the lower surface

Figure 15: Evolution of the equivalent plastic strain for a path of the lower surface using different groove angles.

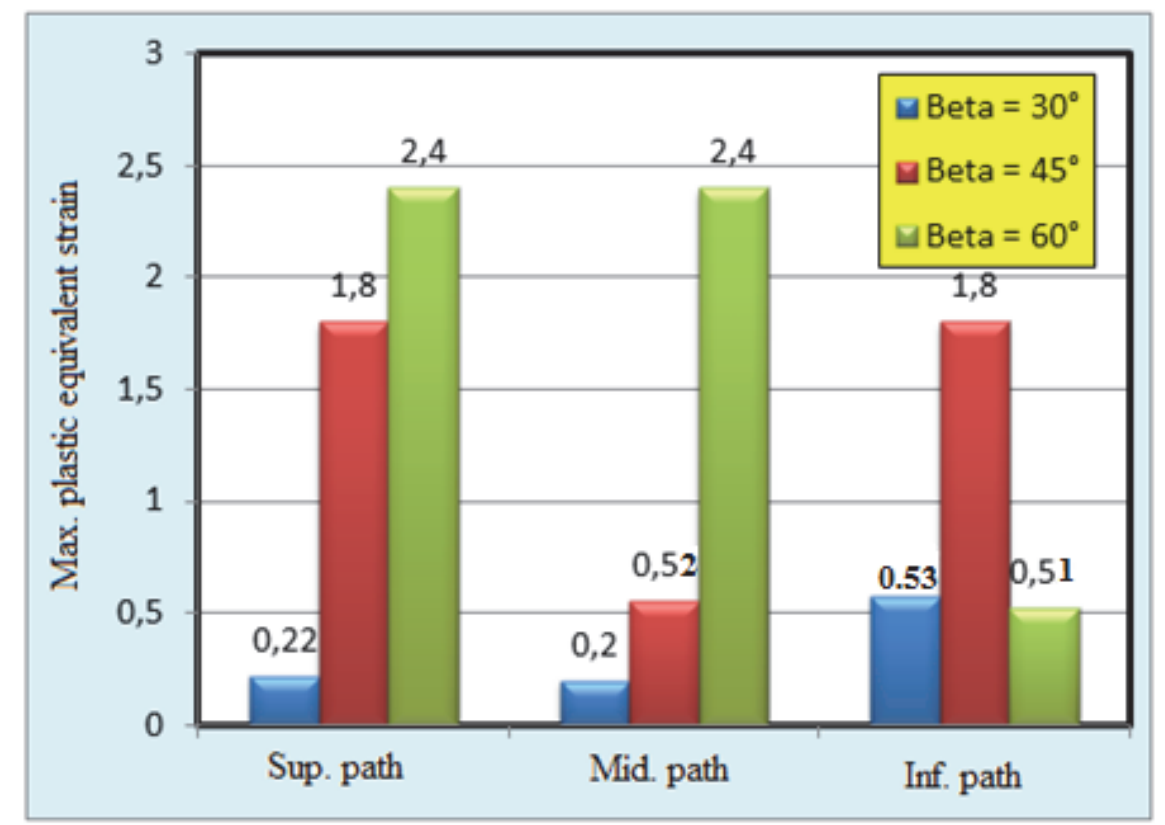

Figure 16: Evolution of maximum equivalent plastic deformations for different angles of the die groove.

\section{Case of a path of the upper face}

Fig. 18 shows the evolution of equivalent plastic strain along a path on the upper surface for different values of the depth of the groove. It can be noted that the highest level of plastic strain is obtained with a depth $\mathrm{H}=5 \mathrm{~mm}$, whereas the lowest level of plastic strain is obtained by the depth of $8 \mathrm{~mm}$. 


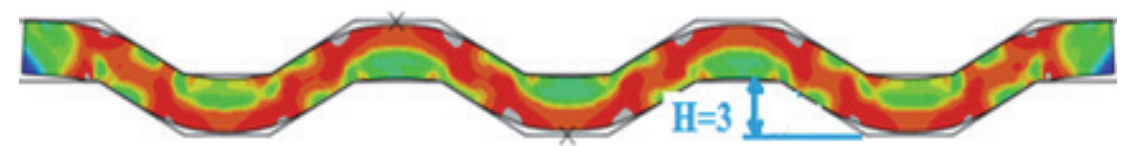

(a)

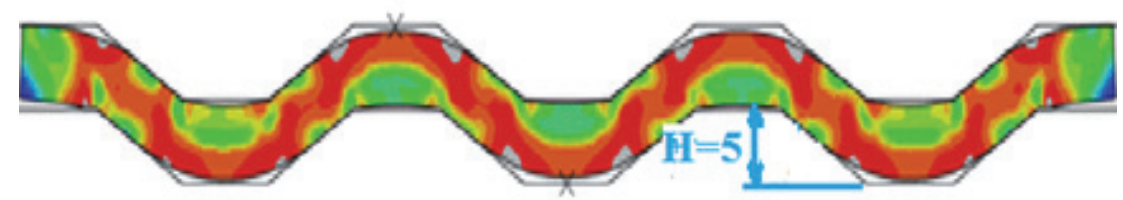

(b)

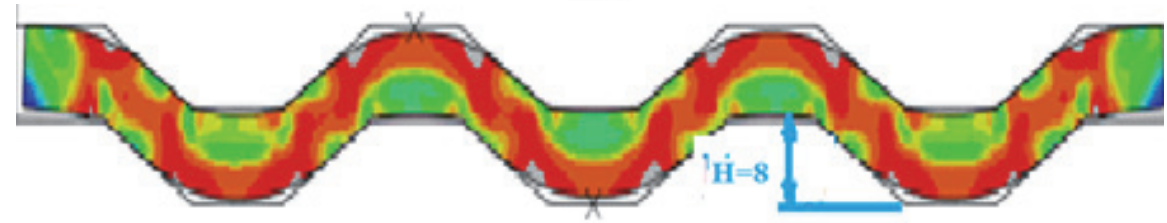

(c)

Figure 17: Illustration of three configurations of the matrices by varying the depth of the groove: (a) $\mathrm{H}=3 \mathrm{~mm},(\mathrm{~b}) \mathrm{H}=5 \mathrm{~mm}$, (c) $\mathrm{H}=$ $8 \mathrm{~mm}$.

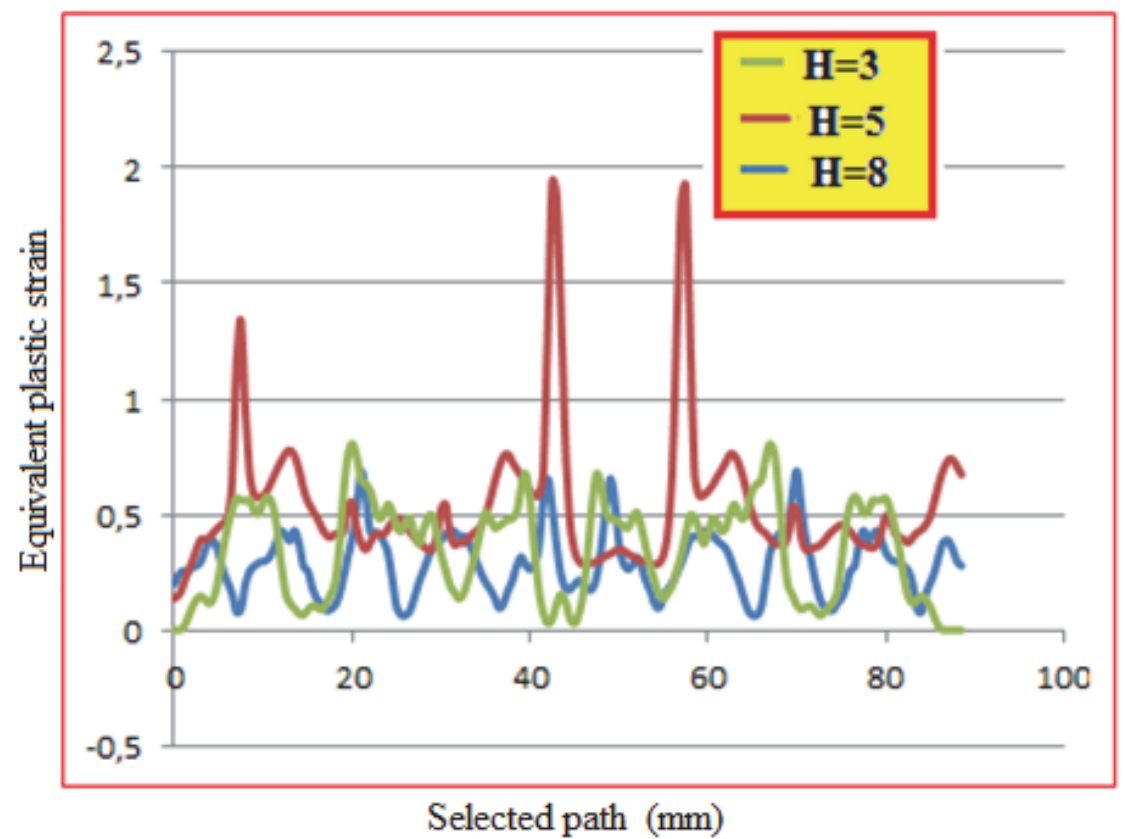

Figure 18: Evolution of the equivalent plastic deformation along a path on the upper surface, using different groove depths.

Case of a path of the middle face

The evolution of the equivalent plastic strain along a trajectory in the middle of the sample using different groove depths is illustrated in Fig. 19. It can be observed that the highest plastic deformations are obtained by a depth of $8 \mathrm{~mm}$, whereas, the lowest values are obtained by $\mathrm{H}=5 \mathrm{~mm}$.

Case of a path of the lower face

Fig. 20 shows the evolution of equivalent plastic strain along a path on the lower surface for different values of the depth of the groove. It can be noted that the highest level of plastic strain is obtained with a depth $\mathrm{H}=5 \mathrm{~mm}$, whereas the lowest level of plastic deformation is obtained by the depth of $3 \mathrm{~mm}$. 


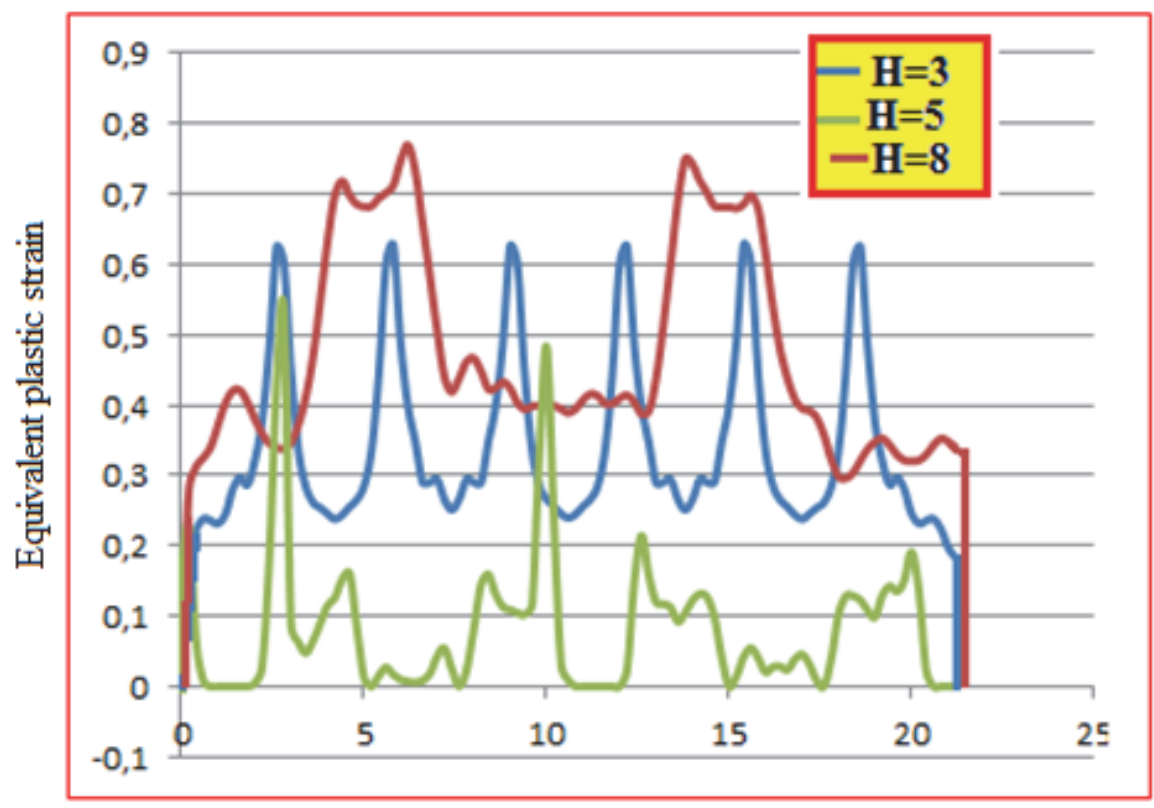

Selected path (mm)

Figure 19: Evolution of equivalent plastic deformation along a path on the middle of the sample using different groove depths.

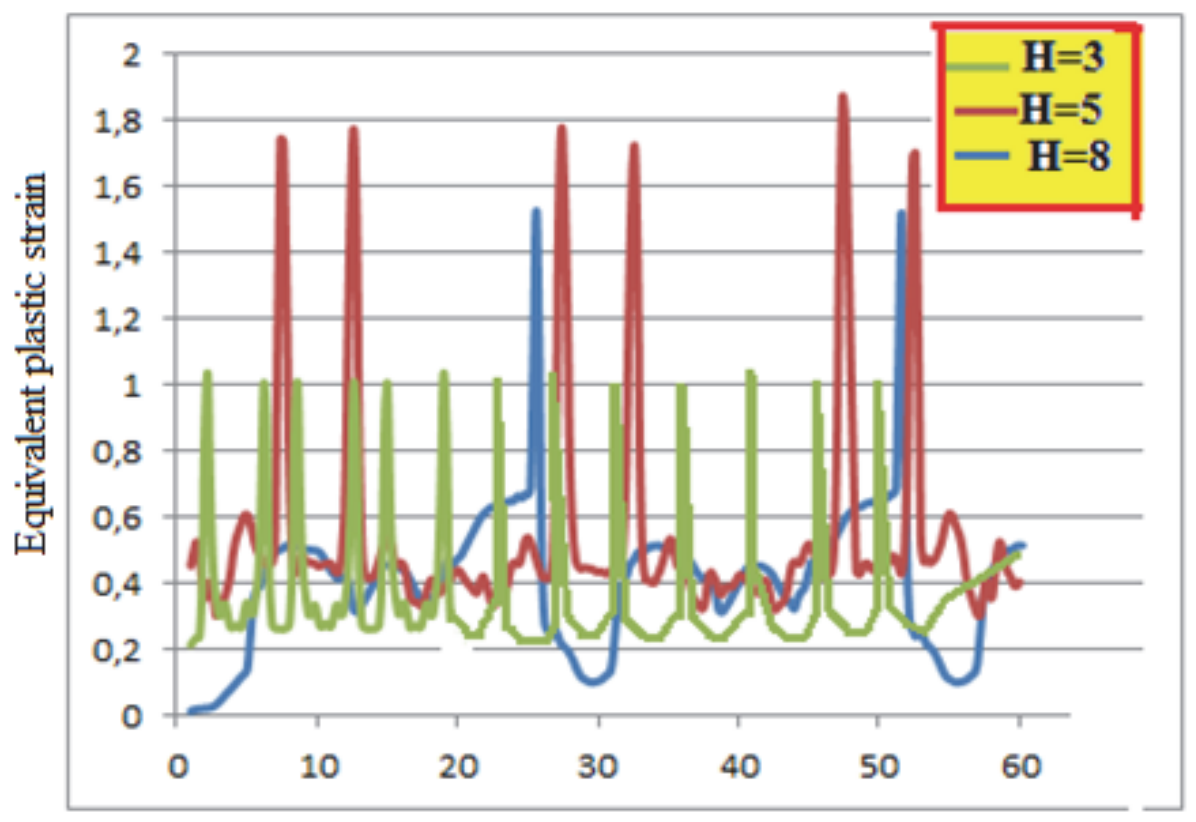

\section{Selected path (mm)}

Figure 20: Evolution of the equivalent plastic deformation along a path on the lower surface, using different groove depths

Fig. 21 summarizes the different results of the maximum values of equivalent plastic strain for different depth values of the groove. It can be noted that the highest values are obtained at the lower and upper surfaces with a depth $\mathrm{H}=5 \mathrm{~mm}$ while the lowest values are obtained in the middle of the sample. For this surface the maximum equivalent strain is obtained by a groove with depth of $8 \mathrm{~mm}$. 


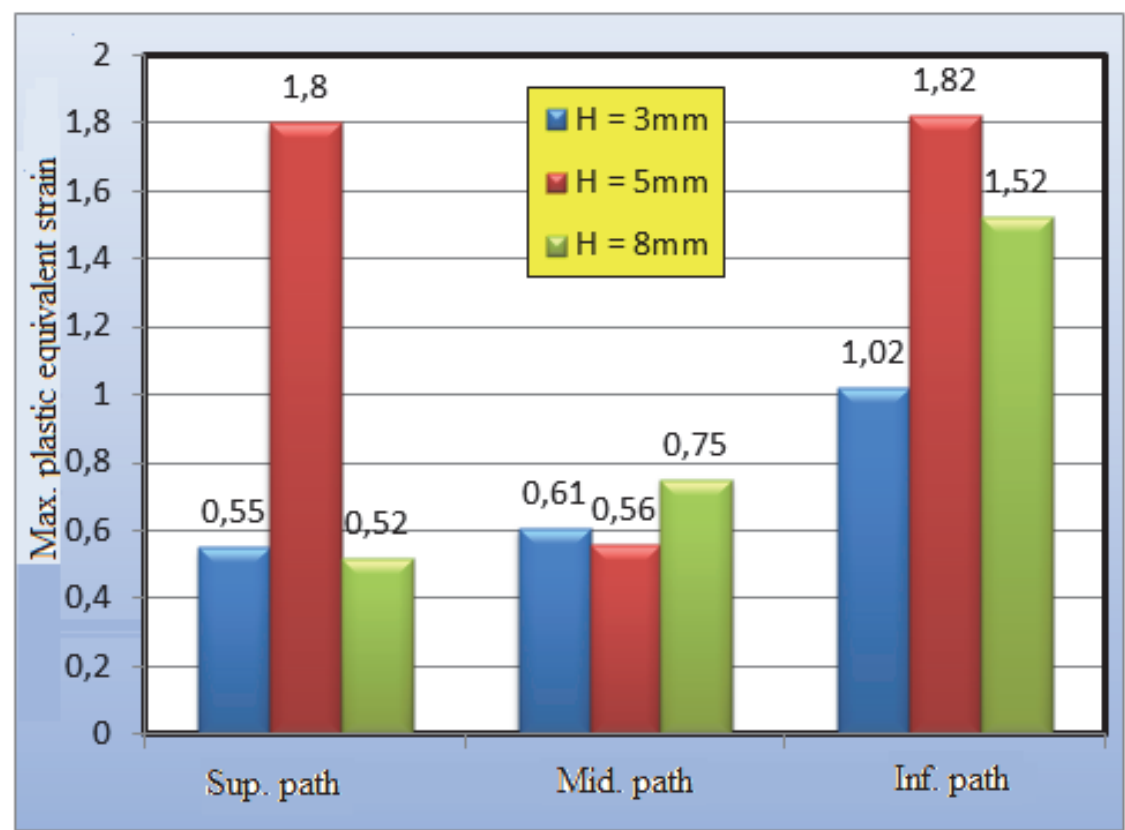

Figure 21: Evolution of maximum equivalent plastic deformations for different depths of the die groove.

\section{CONCLUSION}

he objective of this work was devoted to the numerical study of the CGP process for a typical semi-crystalline polymer which is polyamide (PA66). The effects of the main parameters, such as, the number of cycles, the angle of the groove and its depth have been highlighted. From the results obtained, we can draw the following conclusions:

$>$ In the general case, the equivalent plastic strain induced in the samples increases with the increase in the number of cycles applied.

$>$ The maximum values of the equivalent plastic strain on the paths of the upper and lower surfaces are much greater than that of the path taken in the middle of the sample.

$>$ The angle of inclination of the groove of the CGP dies significantly influences the evolution of the equivalent plastic strain. Indeed, to obtain a relatively high level of plastic strain with a good homogeneity of distribution, it is recommended to use a $45^{\circ}$ angle.

$>$ The groove depth of the CGP dies has a remarkable influence on the PA 66 equivalent plastic deformation. For a $3 \mathrm{~mm}$ thick plate, we found that a depth of $5 \mathrm{~mm}$ ensures the highest level of plastic deformation. High on the upper and lower surfaces. In the middle of the sample, it is the depth of $8 \mathrm{~mm}$ that achieves the highest level of plastic deformation.

\section{REFERENCES}

[1] Bennouna, M. S., Aour, B., Bouaksa, F., Hamzaoui, S. (2018). Experimental Investigation of Mechanical Behavior of a Polyamide before and after Constrained Groove Pressing Process, International Journal of Engineering Research in Africa, pp. 25-36. DOI: 10.4028/www.scientific.net/JERA.36.25.

[2] Yang, H., Wang, M., Guo, L.G., Sun, Z.C. (2008). 3D coupled thermo-mechanical FE modeling of blank size effects on the uniformity of strain and temperature distributions during hot rolling of titanium alloy large rings. Comput Mater Sci, pp. 611-621. DOI: 10.1016/j.commatsci.2008.04.026.

[3] Lee, J.W., Park, J.J. (2002). Numerical and experimental investigations of constrained groove pressing and rolling for grain refinement, J Mater Proc Technol, pp. 208-213. DOI: 10.1016/S0924-0136(02)00722-7. 
[4] Lee, H.R., Sutcliffe, M.P.F. (2004). Finite element modelling of the evolution of surface pits in metal forming processes, J Mater Proc Technol, pp. 391-396. DOI: 10.1016/S0924-0136(02)00722-7.

[5] Kim, T.S., Kuwamurab, H. (2007). Finite element modeling of bolted connections in thin-walled stainless steel plates under static shear. Thin-Walled Struct, pp.407-421. DOI: 10.1016/j.tws.2007.03.006

[6] Lopesa, A.B., Barlatb, F., Gracioc, J.J., Duarted, J.F.F., Rauch,e E.F. (2003). Effect of texture and microstructure on strain hardening anisotropy for aluminum deformed in uniaxial tension and simple shear. Int J Plast, pp.1-22. DOI: 10.1016/S0749-6419(01)00016-X.

[7] Prasad G.V., Goerdeler M., Gottstein G. (2005). Work hardening model based on multiple dislocation densities, Mater Sci Eng, pp. 231-233. DOI: 10.1016/j.msea.2005.03.061.

[8] Bardenhagen, S.G., Stout, M.G., Gray, G.T. (1997). Three-dimensional, finite deformation, viscoplastic constitutive models for polymeric materials, Mechanics of Materials, pp. 235-253. DOI: 10.1016/S0167-6636(97)00007-0.

[9] Frank, G.J., Brockman, R.A. (2001). A viscoelastic-viscoplastic constitutive model for glassy polymers, International Journal of Solids and Structures, pp. 5149-5164. DOI: 10.1016/S0020-7683(00)00339-5.

[10] Colak, O.U. (2005). Modelling deformation behaviour of polymers with viscoplasticity theory based on overstress, International Journal of Plasticity, pp. 145-160. DOI: 10.1016/j.ijplas.2004.04.004.

[11] Aour, B. (2007). Investigation of ECAE process of semi crystalline polymers by a finite element and a coupled boundary element-finite element approach, Thesis of doctorat in mechanical engineering, Université des Sciences et de la Technologie d'Oran, Algérie.

[12] Aour, B., Zairi, F., Nait-Abdelaziz, M., Gloaguen, J.M., Rahmani, O., Lefebvre, J.M. (2008). A computational study of die geometry and processing conditions effects on equal channel angular extrusion of a polymer, International Journal of Mechanical Sciences, pp. 589-602. DOI: 10.1016/j.ijmecsci.2007.07.012.

[13] Aour, B., Mitsak, A. (2016). .Analysis of plastic deformation of semi-crystalline polymers during ECAE process using $135^{\circ}$ die, Journal of Theoritical and Applied Mechanics, 54(1), pp. 263-275. DOI: 10.15632/jtam-pl.54.1.263.

[14] Mitsak, A. (2017). Contribution à la modélisation du comportement des polymères solides au cours du processus d'extrusion angulaires à égales sections, Thesis of doctorat in mechanical engineering ENPOran Algeria

[15] Draï, A., Aour, B. (2013). Analysis of plastic deformation behavior of HDPE during high pressure torsion process, Engineering Structures, pp. 87-93. DOI: 10.1016/j.engstruct.2012.06.033.

[16] Mckenzie, P.W.J., Lapovok, R., Estrin, Y. (2007). The influence of back pressure on ECAP processed AA 6016: modeling and experiment, Acta Mater, pp. 2985-2993. DOI: 10.1016/j.actamat.2006.12.038.

[17] Hosseini, E., Kazeminezhad, M. (2008). A hybrid model on severe plastic deformation of Copper, Compute Mater Sci, pp. 1107-1115. DOI: 10.1016/j.commatsci.2008.07.024.

[18] Aretz, H., Luce, R., Wolske, M., Kopp, R., Goerdeler, M., Marx, V. (2000). Integration of physically based models into FEM and application in simulation of metal forming processes, Modell Simul Mater Sci Eng, pp.881-891.

DOI: $10.1088 / 0965-0393 / 8 / 6 / 309$. 